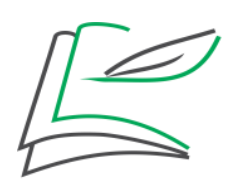

Entretextos

Entretextos 21(1): jan./jun. 2021

ISSN 1519-5392 UEL

DOI: $10.5433 / 1519-5392.2021 v 21$ n1.p.239

\title{
Acesso às informações sobre a Covid-19 pelos Surdos de Teresina-PI, no período inicial da quarentena, deflagrada pela pandemia do SARS-COV2
}

\author{
Access to information about Covid-19 by deaf people from Teresina-PI, \\ during the initial quarantine period triggered by the New Coronavirus \\ pandemic
}

Acceso a información sobre el Covid-19 por parte de Sordos de TeresinaPI, en el período de cuarentena inicial, desencadenado por la pandemia de SARS-COV2

Ana Cristina de Assunção Xavier Ferreira* Francisca Neuza de Almeida Farias*
(Dhttps://orcid.org/0000-0002-0303-7808 (D)https://orcid.org/0000-0002-0109-9749

RESUMO: A atual crise na saúde pública tem chamado a atenção de toda a população. A Covid-19 chega ao Brasil, várias ações e recomendações para o enfrentamento dessa doença começam a ser compartilhadas pelos meios de comunicação. Nesse processo, a comunicação tem sido um forte aliado no combate ao vírus. No entanto, o país dispõe de uma população que faz uso exclusivo da Língua Brasileira de Sinais (Libras), os Surdos. Estes indivíduos precisam ser informados e compreender os conteúdos compartilhados, para que possam fazer a adoção das medidas orientadas pelo Ministério da Saúde. Considerar a Libras para os surdos é possibilitar condições de igualdade. $O$ objetivo deste artigo é investigar, na perspectiva do Surdo, como as informações ao combate da Covid-19 estão sendo disponibilizadas nos meios de comunicação. O estudo é de natureza qualitativa, descritivo, tendo como instrumento de aplicação e coleta de dados o Questionário. Entre os resultados, destacam-se a ausência de intérpretes por meio da janela de Libras e o compartilhamento de conteúdos falsos. Além disso, o acesso às informações da sua região vem sendo inviabilizado pela ausência do tradutor e intérprete de Língua de Sinais/Língua Portuguesa.

PALAVRAS-CHAVE: Informações. Surdos. Covid-19.

ABSTRACT: The current crisis in public health has drawn the attention of the entire population. Covid-19 lands in Brazil, several actions and recommendations for coping with this disease, shared by the media. In this process, communication has been a strong ally in fighting the virus. However, the country has a population that makes exclusive use of the Brazilian Sign Language (Libras), the Deaf people. These need to be informed and covered by the shared

\footnotetext{
* Mestre em Educação pela Universidade Federal do Piauí. Professora de Libras da Universidade Federal do Maranhão. E-mail: crispedagoga2016@gmail.com

* Doutora em Educação pela Universidade Federal do Piauí. Professora de Libras da Universidade Estadual do Piauí. E-mail: neuzafarias@yahoo.com.br
} 
contents, so that they can take the measures recomended by the Ministry of Health. Consider Libras for the deaf and enable equal oportunities. The purpose of this research is to investigate, from the perspective of the Deaf, how the information to combat a Covid-19 is being made available in the media. The study is of a qualitative, descriptive nature, using the Questionnaire as an instrument. Among the results, the absence of Libras' interpreters at video content and the sharing of false content stands out. In addition, access to information in your region has been rendered unfeasible by the absence of the sign language/oral language translator /interpreter.

KEYWORDS: Information. Deafness. Covid-19.

RESUMEN: La actual crisis de salud pública ha llamado la atención de toda la población. Llega el Covid-19 a Brasil, varias acciones y recomendaciones para enfrentar esta enfermedad comienzan a ser compartidas por los medios. En este proceso, la comunicación ha sido un fuerte aliado en la lucha contra el virus. Sin embargo, el país tiene una población que hace uso exclusivo de la Lengua de Señas Brasileña (Libras), los Sordos. Estos individuos necesitan estar informados y comprender los contenidos compartidos, para que puedan adoptar las medidas orientadas por el Ministerio de Salud. Considerar Libras para sordos es posibilitar condiciones de igualdad. El objetivo de esta investigación es investigar, desde la perspectiva de las personas sordas, cómo la información para combatir el Covid-19 está disponible en los medios de comunicación. El estudio es de carácter cualitativo, descriptivo, utilizando el Cuestionario como instrumento. Entre los resultados, destacamos la ausencia de intérpretes de Libras y el intercambio de contenido falso. Además, el acceso a la información en su región se ha vuelto inviable por la ausencia del traductor e intérprete de lengua de señas/legua orale.

PALABRAS CLAVE: Información. Sordera. Covid-19.

\section{Introdução}

A Língua Brasileira de Sinais, doravante Libras, tem sido bastante pesquisada na atualidade, por isso o idioma tem ganhado cada vez mais força e visibilidade no mundo globalizado, principalmente após seu reconhecimento legal, por meio do dispositivo de no 10.436/2002. Após essa conquista, os surdos brasileiros começaram a ter voz e sua presença notada na sociedade, saindo da invisibilidade que predominou no passado.

A Libras é reconhecida como meio legal de comunicação e expressão e tem outros recursos de expressão a ela associados, como sendo uma língua de modalidade visual-espacial, com estrutura gramatical própria, e constituir um sistema linguístico de transmissão de ideias e fatos, oriundos de comunidades de pessoas surdas do Brasil (BRASIL, 2002). É por meio desta língua que os surdos se comunicam, expressam/compartilham suas emoções, sentimentos e, por conseguinte, interagem com a sociedade. Sobre isso, Quadros (2004, p. 10) complementa explicando que "o surdo é o indivíduo que percebe o mundo por meio de experiências visuais".

Por muito tempo, os surdos foram inferiorizados e privados de exercerem a 
comunicação com outros indivíduos/sujeitos sociais em sua língua materna (LODI et al, 2012), contudo, após o reconhecimento dos dispositivos legais mencionados em momento anterior, sua história ganhou novas cenas, logo, o uso e a difusão da Libras se fortaleceu nas pesquisas em todo o país, bem como a motivação e a criação de novas políticas públicas inclusivas.

Um importante diploma que antecedeu a Lei de Libras e o Decreto no $5.626 / 2005$ e contribuiu com o surgimento de outros dispositivos foi a Lei $n^{0} 10.098$, que contempla a Lei da Acessibilidade (BRASIL, 2005a). Este dispositivo estabelece critérios para a promoção da acessibilidade e um destes está relacionado ao acesso aos sistemas de comunicação e sinalização, conforme pode ser constatado no Artigo 17:

O Poder Público promoverá a eliminação de barreiras na comunicação e estabelecerá mecanismos e alternativas técnicas que tornem acessíveis os sistemas de comunicação e sinalização às pessoas portadoras de deficiência sensorial e com dificuldade de comunicação, para garantirIhes o direito de acesso à informação, à comunicação, ao trabalho, à educação, ao transporte, à cultura, ao esporte e ao lazer (BRASIL, 2005a, p. 5).

Percebemos que muitos avanços são notados desde o reconhecimento da língua, no entanto, a existência de barreiras na comunicação é grande, principalmente, quando se trata da interação entre pessoas surdas e ouvintes. Outro dispositivo legal que aborda este acesso e institui a eliminação de barreiras é a Lei no 13.146/2015 - A Lei Brasileira de Inclusão (LBI), em seu artigo 9, inciso $V$, "acesso a informações e disponibilização de recursos de comunicação acessíveis" (BRASIL, 2015).

Referente às Leis, o surdo tem direito ao acesso à comunicação e, quando essa se efetiva, a barreira é rompida, caso contrário, permanece a desinformação e, assim, esta predominará entre os surdos. Para que a comunicação com a pessoa surda seja bem sucedida, sua língua legítima precisa ser utilizada, ou como diz Silva (2002, p. 28), "a língua dos surdos está no sinal, é por meio dele que o sujeito surdo compreende e interfere no mundo".

Uma figura que surge para possibilitar a interação da pessoa surda com ouvintes, é o profissional tradutor e intérprete de Língua de Sinais/Língua Portuguesa (TILS/LP), o qual tem um papel relevante. Nas palavras de Santos e Nogueira (2018, p. 179), 
Os tradutores-interpretes passam a ser os responsáveis pela informação e pelos conteúdos interpretados, tem se tornado uma necessidade para a efetivação na inclusão do sujeito surdo, portanto sua atuação se torna imperativa, ganhando força numa dimensão desmedida.

Para Quadros (2004, p. 13), o profissional "por muitas décadas atuou na informalidade centrado com maior frequência nas instituições religiosas em atividade voluntária".

Este cenário começou a tomar novos rumos à medida que as pessoas surdas conquistavam seus direitos e espaços na sociedade, através dos movimentos sociais (MARTINS, 2009). Portanto, verificamos que a atuação desse profissional requer competências técnicas e boa fluência, e, além destas, é importante o envolvimento com a comunidade surda para uma compreensão acerca das peculiaridades da cultura surda e das diferentes identidades que se constroem no bojo das interações sociais. Nesse sentido, "não basta o profissional ter conhecimento da língua, mas ter boa fluência e ser versátil para interpretá-la para a Língua Portuguesa e vice-versa" (QUADROS, 2004, p. 269).

Corroborando com a autora mencionada, Lacerda (2012), complementa que é necessário este profissional saber usar a Língua de Sinais, doravante Libras, e a Língua Portuguesa (LP) nos diversos contextos e com diferentes interlocutores para fazer ponte entre eles, além de dominar técnicas de interpretação em ambas as línguas.

O TILS/LP tem contribuído para que os surdos não fiquem aquém das informações, no entanto, quando o profissional responsável pela mediação não entra em cena, os prejuízos na compreensão são inevitáveis, visto que muitos surdos não dominam a estrutura linguística do Português Brasileiro (PB) da norma padrão (ALMEIDA; NUNES, 2012) e, por isso, a legenda ou a disponibilização de textos não possibilita a compreensão das matérias veiculadas. Além do mais, muitos conteúdos expostos nos veículos de comunicação são importantes como já comentado por nós, pois alguns deles contém orientações e medidas a serem tomadas, embora, nos questionemos se a forma de transmissão de tais informações contemplam a pessoa surda.

De acordo com as estimativas do IBGE (2010), o Brasil possui cerca de 10 milhões de surdos ou pessoas com deficiência auditiva, sendo considerado um número, ainda, bastante expressivo, e desse cômputo total muitos só conseguem realizar a 
comunicação utilizando a Libras, em uma realidade na qual a maioria das informações, pronunciamentos e orientações disponibilizadas para sociedade são em outra língua , resultando em uma inacessibilidade de informações.

Em nosso contexto atual, o mundo vem enfrentando uma grave crise na saúde pública, com o surgimento de uma doença que nos obriga ao isolamento social, e, dessa forma, cerceia o contato habitual com outros indivíduos. À luz desta eventual realidade, em 30 de janeiro de 2020, a Organização Mundial da Saúde (OMS) declarou emergência de saúde pública de importância internacional, decretando a Pandemia ${ }^{1}$ pelo novo Coronavírus (Sars-CoV-2). Assim, nas palavras de Santos (2020, p. 49) "Uma pandemia desta dimensão causa justificadamente comoção mundial".

O referido surto da doença levou e ainda tem levado muitas vidas, ou seja, é crescente o número de vítimas em razão da doença provocada pelo vírus da Covid-19, até o momento desta escrita, já com suas variantes espalhadas pelo mundo. A exemplo disso, até o dia 23 de maio, na época da coleta de dados, o Brasil já havia ultrapassado o número de trezentos e quarenta e sete infectados pela Sars-Cov-2 e registrado mais de vinte e duas mil mortes. Em 10 de outubro, foram confirmados cinco milhões, cinquenta e cinco mil, oitocentos e oitenta e oito casos; e cento e quarenta e nove mil, seiscentos e trinta e nove óbitos (MINISTÉRIO DA SAÚDE, 2020, p. s./n.).

Em decorrência do contato próximo da pessoa infectada com as demais, o contágio acontece, por meio da eliminação de gotículas pelo nariz e boca, desse modo, Severo (2020) menciona que a Covid-19 não acomete todos da mesma forma, logo, não atingindo os corpos da mesma forma, isto é, com os mesmos sintomas. Por isso, acreditamos que não é nosso propósito aprofundar no detalhamento das características especificas e epidemiológicas da Covid-19, e sim entender como as informações veiculadas sobre essa doença chegam à população surda do Brasil, especificamente à capital do Piauí. Nesse sentido, a problemática deste artigo parte das seguintes inquietações: (i) como as informações disponibilizadas nos meios de comunicação sobre a Covid-19 estão chegando aos Surdos? (ii) E, como os surdos estão adotando medidas preventivas no combater a Covid-19?

\footnotetext{
1 "O termo pandemia" se refere à distribuição geográfica de uma doença e não à sua gravidade. A designação reconhece que, no momento, existem surtos de Covid-19 em vários países e regiões do mundo (OMS).
} 
No Brasil, este vírus chegou em 26 de fevereiro de 2020, mais propriamente na data de:

[...] 3 de Março havia 488 casos suspeitos notificados, 2 confirmados e 240 descartados no país, sem evidência de transmissão local. Os dois primeiros casos confirmados eram de indivíduos do sexo masculino, residentes na cidade de São Paulo - SP, que haviam regressado de viagem à Itália (CRODA; GARCIA, 2020, p. 1).

Informações a respeito da Covid-19 estão sendo veiculadas nos meios de comunicação por representantes do Ministério da Saúde e da Vigilância em Saúde do país. Nestes pronunciamentos, a acessibilidade para os surdos apresenta falhas, pois o acesso às informações, realizado por eles, não acontece de maneira frequente, e, em alguns destes momentos, a presença do TILS/LP não é visível.

Em relação aos infectados no Brasil, ficou evidente que "a rapidez com que o vírus se espalha é impressionante, muitos países não estão preparados para detê-lo, ou mesmo frear a propagação e evitar o colapso do sistema de saúde" (TOSTES; MELO FILHO, 2020, p. 11). Com isso, o sistema de saúde buscou estratégias imediatas para o atendimento a estas pessoas, considerando nesse meio, e nesse curto espaço de tempo as fragilidades existentes, "mas o novo coronavírus surge em um contexto em que o sistema atual já se encontrava com uma legitimidade bastante fragilizada, não só no Brasil, mas em várias partes do mundo" (TOSTES, 2020, p. 33).

Como apresentado anteriormente, a Libras precisa fazer parte desse processo, pois é perceptível a gravidade da referida doença, delineando-se como uma situação que precisa ser compreendida pela comunidade surda. Neste cenário, 03 de out de 2020. Brasil luta para conter a propagação e traça estratégias diariamente que visem a diminuição do número de infectados e, principalmente, do número de mortes. Assim, vem intensificando junto à população a adoção de medidas preventivas para combater este vírus.

De acordo com a Organização Mundial da Saúde, (2020, p. 220), a contenção da Covid-19 dá-se por meio do distanciamento social, porque, no momento, não existe vacina que comprove sua longa eficácia contra a Covid-19, ou medicamentos específicos comprovados. Para Tostes "evidentemente precisamos aderir à ideia de isolamento físico e nesse sentido dar suporte até mesmo às campanhas midiáticas que reduzem o esforço conjunto a algo do tipo "todos contra o vírus". 
Dispondo de todas estas orientações, o contágio pode ser evitado, entretanto, como estas informações não são veiculadas para as pessoas surdas, neste contexto, falantes de Libras, estes falantes acabam por não conhecer quais são as medidas sanitárias de barreira contra o vírus que se apresenta como altamente transmissível. Portanto, se a adoção dessas medidas não for realizada, eles serão possíveis transmissores do vírus e não podemos cobrar da população surda ações preventivas se não Ihes são garantidos o acesso às informações essenciais.

Muitos são os questionamentos a respeito da acessibilidade das informações para este público, pois, embora disponhamos de dispositivos legais que garantem o acesso à elas, a aplicabilidade destes instrumentos apresenta falhas. Diante do contexto atual de pandemia que o mundo vive, o olhar da sociedade para estas pessoas necessita ser igualitário, com o implemento de que devem ser pensadas de modo a incluir estes sujeitos.

Muitos estados brasileiros adotaram medidas de isolamento social, uma vez que "a recomendação de isolamento social, quarentena ou mesmo lockdown" são mecanismos que minimizam ou impedem a movimentação das pessoas (ALMEIDA, 2020). Ainda para este mesmo autor, é necessário controlar o deslocamento da população, com o objetivo de conter o avanço e as consequências da pandemia.

Diante disso, a publicação de Decretos com ações para conter a propagação do vírus está sendo implementada e divulgada, a exemplo disso, o uso máscaras tornou-se obrigatória por todos, em decorrência do crescimento de casos da Covid-19. Logo, o que antes se restringia apenas para as pessoas infectadas e profissionais da saúde, agora passou a ser regra geral. A respeito das medidas supracitadas, questionamosmos sobre como os surdos tomaram conhecimento da doença pandêmica e se estes fizeram a adoção do item em seu cotidiano.

Em uma sociedade majoritariamente ouvinte, é importante compreender como o surdo pode se relacionar, isto é, e como aqueles que não ouvem podem efetivar a comunicação (SILVA, 2012). Sobre isso, percebe-se que este público ainda está à margem da sociedade predominante e que os recursos indispensáveis para a informação chegaram até eles não são disponibilizados ou se resumem a alguns assuntos.

Sobre este cenário, a referida realidade se complica em muitos estados do país. 
No Piauí, a população estimada é de 3.273 .227 pessoas e, desta população, 185.975 apresentam problemas auditivos. Na capital, Teresina, este número chega a quase 43.000 indivíduos (IBGE, 2010). Consideramos que na capital o acesso às informações é mais fácil, pois a cidade dispõe de quatro emissoras de televisão, porém, a acessibilidade em muitas situações não acontece, principalmente no atual momento de Pandemia que o país enfrenta.

Em Teresina, devido às medidas prévias adotadas pelos representantes públicos, a propagação da Covid-19 pode ser contida e sua velocidade controlada, se comparada com as demais capitais do Nordeste. Contudo, o cenário atual vem mostrando um crescimento nos números de infectados e, de acordo com a Secretária de Saúde do Estado do Piauí (SESAPI), até o dia trinta de maio de 2020, o estado apresentou um número de quatro mil novecentos e trinta e um infectados.

A verificação destes dados pode estar atrelada à realização de testes mais frequentes, apesar de haver suspeitas de subnotificação, já que Teresina não dispõe de testes para todos. Para Gomes (2020, p. 53), "O Brasil é o último colocado no mundo em testes por população, o que nos poderia dar não só a exata dimensão da extensão da doença, como o caminho para uma flexibilização futura segura do confinamento".

Em se tratando dos óbitos registrados no estado do Piauí, este número vem crescendo gradativamente, já que, até o penúltimo dia do mês de maio, este número chegou a cento e sessenta e um óbitos e, em outubro deste mesmo ano, foi registrado dois mil duzentos e sessenta e um (PIAUI, 2020).

Neste sentido, os governantes do estado vêm intensificando suas medidas de orientações para a população, assim como pronunciamentos com informações sobre as medidas que estão tomando com relação ao comportamento do vírus no estado. No entanto, em muitos destes momentos, a presença do TILS/LP não é vista, assim, as informações chegam às pessoas surdas por outros meios e, quando chegam, muitas vezes vem com omissões. Na capital, observa-se que os veículos de comunicação não estão pensando em propiciar este acesso para os surdos.

Sobre a atuação segura destes profissionais neste período, a Federação Brasileira das Associações dos Profissionais Tradutores e Intérpretes e Guia-Intérpretes de Língua de Sinais (FEBRAPILS) disponibilizou, em carta aberta, publicada em 18 de março de 2020, as orientações para uma atuação segura. Sabemos que estes profissionais fazem 
uso dos membros superiores para a realização de movimentos e, principalmente que as mãos são as mais utilizadas na interpretação, além de muitos destes sinais tocarem a face, no entanto, as orientações do Ministério da Saúde é que isso deva ser evitado. Desse modo, a Febrapils (2020, p. s./n.) orienta a estes profissionais:

[...] evitem tocar com as mãos em pontos de articulação localizados nas regiões da face. Mas que, preferencialmente, desloquem os sinais para serem realizados em pontos de articulação próximos, mas sem o contato direto com a boca, nariz, testa, ou a região dos olhos.

Neste contexto seguro de atuação, os profissionais estão disponíveis para colaborar e permitir o acesso dos surdos às informações disponibilizadas para a população. Com relação ao quantitativo destes TILS/LP na capital para esta prestação de serviço, a Associação de Profissionais Tradutores e Intérpretes de Língua de Sinais (APILSPI) possui quarenta e cinco filiados. Com base em dados fornecidos pelas instituições educacionais, como o Serviço Nacional de Aprendizagem Comercial (SENAC) e o Centro de Apoio ao Surdo (CAS), na capital, este número aproxima-se de duzentos profissionais formados em ambas as instituições. Ou seja, existe mão de obra qualificada para prestar esta atividade, portanto, para que isso aconteça e sua presença seja assegurada, os dirigentes e os veículos de comunicação precisam pensar e possibilitar o acesso, e se todos contribuírem, os resultados serão mais assertivos.

Atualmente, em Teresina, algumas iniciativas estão sendo tomadas para que isso seja minimizado, uma vez que as instituições estão colaborando para que os surdos tenham acesso às informações, a exemplo, a Universidade Federal do Piauí (UFPI), por meio da coordenação do curso de Licenciatura em Letras Libras, com a disponibilização de conteúdos visuais a respeito da Covid-19. Nota-se que a prefeitura vem tomando pequenas iniciativas a respeito, realizando adaptações em poucos pronunciamentos do prefeito da capital, com o apoio dos TILS/LP da Ação Social Arquidiocesana (ASA). No entanto, entende-se que a ausência de acessibilidade para os surdos nos meios de comunicação em época de pandemia da Covid-19 tem apresentado muitas barreiras e a adoção consciente de medidas preventivas no cotidiano destes sujeitos são desconhecidas e/ou incompletas.

Face ao exposto, este estudo tem como objetivo investigar, na perspectiva do surdo, como as informações ao combater da Covid-19 estão sendo disponibilizadas nos 
meios de comunicação e como está acontecendo a adoção da prevenção por ele, em seu cotidiano.

\section{Metodologia}

O aporte metodológico deste artigo pauta-se em uma pesquisa de natureza qualitativa, do tipo descritiva. Para aplicação do questionário, selecionamos 10 (dez) surdos, todos usuários de Libras, de acordo com os seguintes critérios: 1) idade mínima de 18 anos; 2) escolaridade mínima: Ensino Médio (a partir do $2^{\circ}$ ano); 3) domínio em Libras; e 4) residir na cidade de Teresina-PI. O convite aos surdos para participação deste estudo foi realizado em Libras, por meio de vídeo.

O instrumento adotado para coleta das informações foi um questionário elaborado pelas pesquisadoras, utilizando o Google formulários, cuja adoção deu-se em respeito às orientações da OMS mediante o distanciamento físico social. O questionário é composto por 24 (vinte e quatro) perguntas, das quais 13 (treze) foram abertas e 14 (quatorze) fechadas, com o aceite de apenas uma única resposta. Com relação às questões, estas foram elaboradas com base no direcionamento fornecido pelos objetivos da pesquisa.

Em se tratando dos critérios estabelecidos neste artigo, buscou-se selecionar participantes com um nível de escolaridade mínimo que garantisse que a compreensão das mensagens não fosse limitada. Sobre a idade dos participantes, selecionou-se aqueles que possuíam maioridade legal, a fim de que o aceite na participação da pesquisa se desse a partir do próprio participante.

\section{Análise}

Os participantes da pesquisa deram seu aceite por meio do próprio questionário, o qual apresentava, em sua primeira pergunta, um texto no qual se esclarecia todas as etapas da entrevista escrita. Além disso, continha informações acerca dos riscos (mínimos) na participação da pesquisa, bem como o fato de os sujeitos estarem livres para desistir e retirar a sua participação a qualquer momento. Apenas após este procedimento, que se confirmava quando o sujeito clicava em 'eu aceito', é que se dava início ao acesso às demais perguntas. No texto, os sujeitos foram identificados com pseudônimos, com o intuito de resguardar as suas identidades. 
Em se tratando do perfil dos participantes, verificamos que $50 \%$ são do sexo masculino e a outra metade do sexo feminino, 60\% possuem Ensino Superior, 20\% Ensino Médio completo, 10\% Ensino Médio incompleto e 10\% Ensino Superior em andamento. Contudo, é importante ressaltar, que a maioria dos participantes concluíram o curso de Licenciatura em Letras/Libras, fato que contribui para uma ampla compreensão acerca do objeto de estudo desta pesquisa, uma vez que o nível de leitura e de capacidade reflexiva também se aprimoram com o desenvolvimento de estudos.

Os participantes com domínio de Libras foi um dos critérios propostos por nós. A faixa etária ficou entre 18 a 40 anos, sendo que Marlee é a mais nova e ainda está no ensino médio. Sobre a formação especifica na área de Libras dos participantes deste estudo, 60\% apresentam especialização em Libras, com docência no ensino superior. Para Farias e Lustosa (2018), a comunidade linguística surda tem dado grandes saltos nos últimos anos, pois na Antiguidade esta realidade era bem diferente, já que a pessoa surda era considerada incapaz e vivia à margem da sociedade predominante, a ouvinte. $\mathrm{Na}$ atualidade, a pessoa surda tem tido oportunidade de acesso à educação, contudo ainda há carências, principalmente quanto à comunicação, a qual precisa ser revista. Sendo assim, quando este sujeito tem poder de voz, as possibilidades de interferência são possíveis em busca dos direitos sociais, culturais e linguísticos do povo surdo (DANTAS; ARAúJO, 2018).

Com base no instrumento aplicado junto aos participantes, apresentam-se as subcategorias.

Quadro 1 - Dificuldades no acesso as informações relacionadas a COVID-19

\begin{tabular}{|l|c|c|}
\hline \multicolumn{1}{|c|}{ Subcategorias } & Surd@ & Frequência \\
\hline $\begin{array}{l}\text { Desconhecimento do português como empecilho na } \\
\text { compreensão das legendas }\end{array}$ & Pete, Mille, Bill & 3 \\
\hline $\begin{array}{l}\text { Ausência de janelas de acessibilidade com profissionais } \\
\text { de tradução e interpretação de Libras/português }\end{array}$ & $\begin{array}{c}\text { Halle, Jodie, } \\
\text { Bob }\end{array}$ & 3 \\
\hline $\begin{array}{l}\text { Dificuldades na adaptação da nova rotina para } \\
\text { enfrentamento da COVID-19 }\end{array}$ & $\begin{array}{c}\text { Pete. Rob, } \\
\text { Robert }\end{array}$ & 3 \\
\hline $\begin{array}{l}\text { Dificuldades na interpretação das informações falsas } \\
\text { (FAKE NEWS) }\end{array}$ & $\begin{array}{c}\text { Bill, Pete, Jane, } \\
\text { Marllie }\end{array}$ & 4 \\
\hline
\end{tabular}

Fonte: Elaborado pelas pesquisadoras. 
Ferreira, A. C. A. X.; Farias, F. N. A.

\section{Desconhecimento do português como empecilho na compreensão das legendas}

Uma dificuldade apontada pelos surdos participantes, relacionada com a compreensão do português escrito, está associada à disponibilização de legendas nos aparelhos de TV. Esta função pode ser ativada usando o recurso de acessibilidade Closed Caption, o qual está disponível apenas nos aparelhos modernos, mas para isso, as emissoras de TV precisam oferecer este recurso, e somente assim poderá ser utilizado pelo usuário. No entanto, para $60 \%$ dos participantes, a legenda não atende as suas necessidades linguísticas, devido às dificuldades de os mesmos compreenderem a informação transmitida em língua portuguesa. É sobre este aspecto que apontam os participantes, quando dizem que:

[...] Eu consigo compreender melhor quando a mensagem é passada em Libras, minha L1 (PETE) .

[...] Eu não entendo legenda, sempre tem problemas, não é $100 \%$ bom (MILLE).

[...] Informações para a comunidade surda, tem de ser em língua sinais, eu entendo melhor língua visual (BILL).

Diante deste desafio, os surdos precisam recorrer a outros meios em busca de informações, uma vez que a legenda, por si só, não atende as suas necessidades. Muitas informações disponibilizadas não são compreendidas, o que pode impossibilitar sua aplicação, caso haja caráter de orientação. Nesse sentido, quando a comunicação é assertiva, os surdos agem, criam e recriam um ambiente social de vida (TESKE, 2012).

Sobre isso, estes participantes preferem que as informações sejam repassadas em Libras, devido às dificuldades que tiveram na aquisição do português, durante seu processo inicial de escolarização. Para Mélo, Araújo e Soares (2012), a língua de sinais é o ponto de partida que dará sustentação a todas as reflexões, apreensão e construção de conceitos por este público e possibilita ao surdo integrar-se na comunidade na qual está inserido.

\section{Ausência de janelas de acessibilidade com profissionais de interpretação de}

\section{Libras/português}

A janela é o espaço onde acontece a tradução da Libras realizada pelo Intérprete de Libras/português. Sua localização, geralmente, fica no canto direito da tela, contudo, 
a sua disponibilização deve atender aos critérios estabelecidos pela Norma da Associação Brasileira de Normas Técnicas (2005), (NBR no 15290), a fim de não comprometer a imagem do profissional. "A altura da janela deve ser, no mínimo, metade da altura da tela do televisor e a largura da janela deve ocupar, no mínimo, a quarta parte da largura da tela do televisor". Porém, a janela de Libras não é visualizada com frequência, sua presença é notada mais em programas televisivos de cunho eleitoral partidário, para cumprimento da Lei no. 13.146/2015. Sobre este aspecto, vejamos o que os surdos responderam:

Figura 1- Janela de Libras com informações da COVID-19 na TV

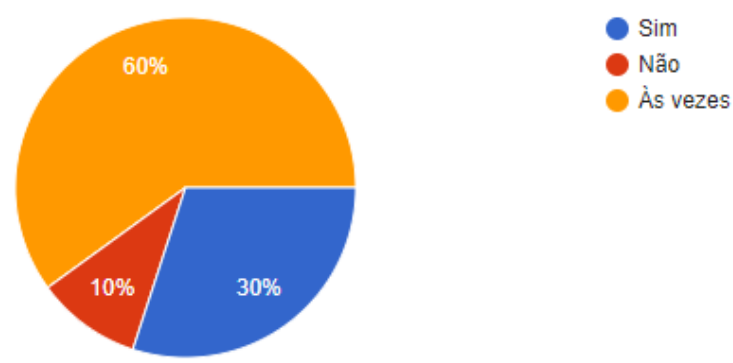

Fonte: Dados da pesquisa.

Sobre este aspecto, $60 \%$ dos participantes informaram que este recurso poucas vezes é ofertado pelos canais de televisão, ou seja, para a maioria das informações disponibilizadas não existe este recurso e, a exemplo disso, citamos as entrevistas com - Ministro da Saúde. Observa-se a presença deste profissional apenas em pronunciamentos feito pelo presidente da república. Em se tratando do tamanho da janela, quando o recurso está disponível, $60 \%$ dos surdos informaram que o tamanho da janela atualmente não está adequado e isso traz alguns prejuízos no entendimento da mensagem. Segundo os participantes, mesmo nos pronunciamentos da presidência, muitas vezes a imagem do profissional é cortada, ficando por algum tempo sem visualização.

Sobre a Covid-19, a exposição tem sido destaque em toda a mídia, principalmente nos jornais televisivos, nesse sentido, para os participantes, o recurso de acessibilidade por meio da janela em Libras é a mais indicada. Sobre esta situação, vejamos o que os participantes informaram: 
[...] Sempre, em informações para surdos, devem usar língua de sinais visual, assim eu entendo a mensagem (JODIE).

[.... A mensagem tem que ser em Libras, para eu entender (HALLE).

[....] A Janela de Libras, com intérprete na TV, eu preciso muito (BOB).

Analisando os depoimentos dos Surdos, verifica-se que a falta deste recurso compromete em sua íntegra a compreensão do que está sendo repassado. Os conteúdos divulgados só chegam quando os mesmos buscam outras formas para saber o que está sendo anunciado. Os entrevistados foram indagados sobre quais estratégias eles buscavam para saber de algum conteúdo considerado por eles não acessível e $33,3 \%$ informaram que os familiares auxiliam na tradução; outros 33,3\% perguntam, posteriormente, para algum intérprete de Libras/português e 22\% disseram que ficam sem saber, pois, os familiares pouco sabem a Libras e apenas $11,1 \%$ utilizam a legenda.

De maneira inesperada, a pandemia foi anunciada e, de forma acelerada, as informações foram sendo apresentadas nos meios de comunicação. Perguntado aos participantes como tomaram conhecimento a respeito da COVID-19, os Surdos disseram:

Figura 2 - Via de acesso a respeito da pandemia da COVID-19
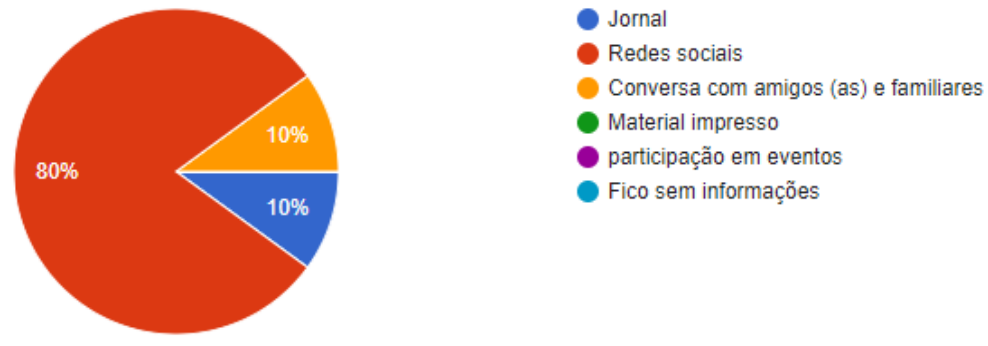

Fonte: Dados da pesquisa.

Observa-se que $80 \%$ tomaram conhecimento através das redes sociais, ou seja, poucos tiveram acesso às informações desta doença pela televisão. Todos os participantes têm acesso à internet e dispõem de redes sociais e, muitos destes produtos, compartilhados pelas redes sociais, estão sendo adaptados com a janela em Libras, por algumas iniciativas particulares e não pelo cumprimento da lei.

Sobre a oferta deste recurso, iniciativas de algumas instituições e dos próprios intérpretes estão sendo oferecidas, nesse sentido, as informações chegam a este 
Acesso às informações sobre a Covid-19 pelos Surdos de Teresina-PI, no período inicial da quarentena, deflagrada pela pandemia do SARS-COV2

público de forma mais compreensível, mas informaram que em alguns destes momentos, o serviço disponibilizado, mesmo que em pouca frequência, apresenta problemas, principalmente nas edições mal realizadas antes da disponibilização para a população. Reforçando isso, Nascimento (2017, p. 4) pontua que a "janela de Libras é observada, por alguns Surdos, como um desejo ainda a ser alcançado".

\section{Dificuldades na adaptação da nova rotina para enfrentamento da Covid-19}

Dentre as recomendações para a prevenção do contágio da Covid-19, o isolamento físico social é a medida mais eficaz para o momento, pois desacelera a propagação do vírus e, assim, diminui a velocidade na curva epidêmica, com vistas a evitar o contágio e o colapso do sistema de saúde. Esta medida tende a reduzir a necessidade de suporte ventilatório e a internação em unidades de terapia intensiva em curto espaço de tempo, adequando a necessidade à capacidade assistencial do sistema de saúde" (RAFAEL et al., 2020, p. 3).

A população precisou se adequar à nova realidade orientada pelos órgãos de saúde e a rotina de muitos brasileiros sofreu alteração, mesmo para aqueles que atuam em estabelecimentos considerados essenciais e que continuam com suas atividades normais. Sobre este aspecto, $100 \%$ dos Surdos participantes informaram que houve mudanças na sua rotina. Dentre elas, pontuaram:

[...] Não posso mais sair de casa para trabalhar, somente funções básicas e de extrema importância (PETE).

[...] Quarentena é para ficar em casa, mas não acostumo muito, porque eu saio sempre para o trabalho e faculdade (ROB).

[...] Outra forma de trabalhar agora, só on-line, também a rotina em casa é sempre igual, porque não posso sair (ROBERT).

Como observamos, mesmo com as orientações, a maioria está mais em suas residências, porém outros continuaram desempenhando suas atividades profissionais, com novas condutas de cunho preventivo, mas todos com o mesmo propósito, evitar o contágio e diminuir a letalidade desta doença. 
Ferreira, A. C. A. X.; Farias, F. N. A.

\section{Dificuldades na interpretação das informações falsas (Fake News)}

Além das dificuldades elencadas, observou-se que neste momento de pandemia do Novo Coronavírus, a população está rodeada de informações sobre a Covid-19, uma vez que a disseminação desses conteúdos é muito rápida. Contudo, neste contexto, muitas dessas informações são falsas, e o seu compartilhamento acontece com maior frequência nas redes sociais, onde os Surdos têm maior acesso às matérias veiculadas.

Devido ao alto índice de fake news sobre a doença, o Ministério da Saúde vem alertando para a checagem das informações e, para auxiliar a população, disponibilizou um número de WhatsApp exclusivo para o envio de possíveis informações falsas recebidas, porém, os participantes dessa pesquisa desconhecem esse tipo de serviço. Com relação a isso, citamos exemplos, como o de que as máscaras doadas pela China estavam contaminadas pelo vírus. Outra preocupante informação divulgada e que vem gerando grandes discussões é a respeito dos medicamentos cloroquina e hidroxicloroquina, cujas notícias falsas afirmam que ambos os itens estão sendo usados no Brasil para combater o vírus de forma satisfatória. Sobre este último, os itens são autorizados, a critério médico, para uso de curto prazo, e sua administração deve ocorrer em pacientes hospitalizados em estado grave (MINISTÉRIO DA SAÚDE, 2020, s.p.).

No compartilhamento desses conteúdos falsos, os prejuízos para a população surda aumentam, porque esse público já sofre com a desinformação, e esses conteúdos circulam livremente no ambiente online e podem causar sérios danos. Quanto a este contexto, $60 \%$ dos participantes da pesquisa informaram sentir dificuldades em identificar conteúdos falsos.

[...] Eu recebo muitas informações pelo celular, vídeos e textos escritos, mas não sei se são verdadeiras ou falsas, eu já compartilhei notícias falsas, enganada (JANE).

[...] As informações sempre chegam pelo celular, não consigo saber se é verdade ou mentira, é difícil (MARLEE).

Sobre as formas de diferenciar os conteúdos verdadeiros dos falsos, $40 \%$ dos Surdos encontram facilidade na identificação, mas reconhecem que a perda de tempo poderia ser evitada, vejamos os que pontuaram: 
Acesso às informações sobre a Covid-19 pelos Surdos de Teresina-PI, no período inicial da quarentena, deflagrada pela pandemia do SARS-COV2

[...] Percebo através das fontes, se é uma fonte confiável ou não (BILL)

[...] Informações da rede social, a maioria são fake news, eu não acredito, mas no jornal sim, o ministro saúde dá informações (PET).

Os Surdos demonstraram preocupação com a quantidade de notícias falsas sobre a Covid-19, assim como a dificuldade para diferenciá-las, pois a velocidade em que elas são repassadas é preocupante para eles. Devido à dificuldade na compreensão do português escrito, pela maioria, muitos desses conteúdos não são entendidos de forma correta e, dependendo da informação, pode ser adotado por eles e assim causar danos a sua saúde. Os participantes informaram que o repasse de notícias falsas pode causar sérios prejuízos, como apresentado nos dados na figura 3 :

Figura 3 - Informações com as notícias falsas sobre a Covid-19

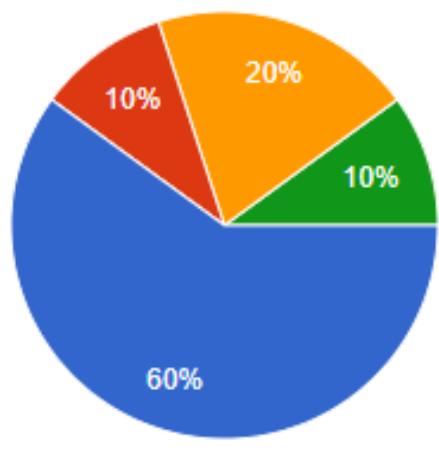

Atrapalha

Não atrapalha

Sempre verifico as informaç̃̃es, a fim de evitar compartilhar notícias falsas

Não tenho acesso, não são disponibilizadas em Libras

Tenho acesso em partes, apenas quando consigo fazer uso da leitura labial

Fonte: Dados da pesquisa.

Para $60 \%$ dos participantes, as fake news sobre a Covid-19 atrapalham muito na compreensão das informações, na interpretação de dados, na adoção de condutas, dentre outros aspectos. Na atual conjuntura, o recebimento de informações têm sido frequente, porém, algumas delas sem veracidade, a grande preocupação é quanto às consequências que podem gerar na vida da pessoa. Muitas notícias são de caráter informativo, principalmente, as que são peculiares de cada região, e o enfrentamento desta pandemia tem sido desafiador para todos. A população surda tem ficado à margem de muitas informações, e o que chega a eles é muito pouco. 


\section{Conclusão}

Considerando a necessidade de comunicação clara frente à pandemia da Covid19, as informações sobre a doença precisam estar disponíveis para a população, incluindo as pessoas surdas, usuárias da Libras. Os conteúdos oferecidos precisam ser acessíveis, possibilitando o entendimento por parte desses indivíduos.

A comunicação para este público, para ser assertiva, precisa ser em Libras e o que se verificou nesse estudo foi a dificuldade de os Surdos terem acesso a todas as informações disponibilizadas pelos veículos de comunicação. Dentre as dificuldades informadas pelos participantes, a ausência de janelas em Libras nos meios de comunicação é a maior delas, principalmente em assuntos relacionados à pandemia. Além do mais, a legenda não atende as suas necessidades, fato esse atribuído à dificuldade no entendimento do português, situação apontada pela maioria, ficando assim comprometida a compreensão dos conteúdos expostos.

A maioria das informações essenciais disponibilizadas para a população teresinense não têm possibilitado o acesso para os Surdos, muitos pronunciamentos diários têm sido realizados sem a presença do profissional TILS/LP, por meio da janela de Libras, o que faz com que esta população desconheça algumas ações e medidas adotadas na cidade, e também muitas destas informações chegam a eles de forma fragmentada.

A falta de comunicação em Libras gera ausência de informações básicas para este público e, na capital do Piauí, segundo os participantes, os governantes não estão preocupados em promover essa acessibilidade, as coletivas são realizadas e o acesso não é viabilizado para eles.

Para minimizar a situação, vídeos educativos estão sendo criados por uma instituição de ensino local com informações relacionadas à Covid-19, para que os Surdos tenham acesso, o que tem amenizado a angústia que muitos sentem em não se sentirem incluídos.

Iniciativas como essa, possibilitam aos Surdos interagir, posicionar-se e compreender os conteúdos formativos relacionados a este vírus, bem como adotar corretamente as medidas protetivas para o enfrentamento da doença. Os participantes ainda relataram que isso gera desconforto e reafirmam que a inclusão eficiente está longe de ser efetivada no Brasil. 
Com a pesquisa, ficaram evidenciadas as dificuldades que os Surdos enfrentam em seu cotidiano relacionadas ao acesso à comunicação, principalmente neste período crítico e grave que toda a população enfrenta. Receber as informações por partes e, muitas vezes, com ruídos também tem sido um fator que dificulta a adaptação da pessoa surda a esse momento de isolamento e à mudança de sua rotina, pois, conforme observamos ainda há o problema das fake news, que dificultam para muitos Surdos a compreensão do que seja verdadeiro ou não.

Muito se tem falado acerca do distanciamento físico social, os benefícios que esta ação traz para o enfrentamento da Covid-19, o acesso com relação ao número de infectados e de mortes no mundo, eles têm isso claro, mas, por exemplo, entender como se interpreta curva de contágio, não, por isso a importância de se utilizar a Libras nesta transmissão.

Observamos, assim, que há necessidade de maiores discussões acerca das políticas públicas vigentes para que sejam criadas formas que possibilitem o acesso desta população a todas as informações. Constatamos ainda, de acordo com as análises realizadas, que existem inúmeras fragilidades neste processo de comunicação disponibilizada. Ficou mais evidente no momento crítico em que o país luta contra uma das suas maiores crises na saúde pública, que a dificuldade na comunicação se estende ainda aos demais espaços, como os ambientes hospitalares. Caso haja infecção da doença em pessoa surda, isso nos leva a refletir sobre como será esta comunicação. Esperamos que estes resultados possam instigar mais pesquisas a respeito dessa temática e, assim, contribuir para o fortalecimento de ações que favoreçam o acesso com equidade a toda a população.

\section{Referências}

ALMEIDA, Débora Ribeiro de; NUNES, Julia Loures. Faraco, C. A. (2008). Norma Culta Brasileira: desatando alguns nós. São Paulo: Parábola Editorial, 196 p. Revista Práticas de Linguagem, Juiz de Fora, v. 2, n. 1, p. 166-169, jan./ jul. 2012 Disponível em: https://www.ufjf.br/praticasdelinguagem/files/2012/10/166-169-Norma-CultaBrasileira.pdf. Acesso em: 3 de out de 2020.

ALMEIDA. Rogério de. Covid-19, o nascimento de um novo século e os laboratórios sociais. Jornal da USP. São Paulo, 15 abr. 2020. Disponível em: https://diz.ae/bIjqs. 
Acesso em: 16 de out. 2020.

ASSOCIAÇÃO BRASILEIRADE NORMAS TÉCNICAS. ABNT NBR-15290: acessibilidade em comunicação na televisão. Rio de Janeiro: ABNT, 2005.

BRASIL. Decreto-lei n. 5.626, de 22 de dezembro de 2005. Regulamenta a Lei $n$. 10.436, de 24 de abril de 2002, que dispõe sobre a Língua Brasileira de Sinais - Libras. Diário Oficial da União, Brasília DF, 23 dez. 2005a.

BRASIL. Lei no 10.098. Estabelece normas gerais e critérios básicos para a promoção da acessibilidade das pessoas portadoras de deficiência ou mobilidade reduzida e dá outras providências. Diário Oficial da União, Brasília DF, 16 out. 2020.

BRASIL. Lei 10.436, de 24 de abril de 2002, que dispõe sobre a Língua Brasileira de Sinais - Libras, e o art. 18 da Lei n. 10.098, de 19 de dez. 2000. Diário Oficial da União, Brasília DF, 23 dez. 2005b.

BRASIL. Lei no. 13.146, de 6 de julho de 2015. Institui a Lei Brasileira de Inclusão da Pessoa com Deficiência (Estatuto da Pessoa com Deficiência). Diário Oficial da União, Brasília, DF, 6 jul. 2015.

CRODA, Julio Henrique Rosa; GARCIA, Leila Posenato. Resposta imediata da vigilância em saúde à epidemia da COVID-19. Epidemiologia e Serviços de Saúde, Brasília, v. 29, n. 1, p. 1-3, 2020. Disponível em: https://doi.org/10.5123/S1679-49742020000100021. Acesso: 07 out. 2020.

DANTAS, M. M. de C.; ARAÚJO, C. S. S de. Surdez e as relações contraditórias da esfera política para emancipação humana do surdo. In: FARIAS, Francisca Neuza de Almeida; LIMA, Ediane Silva (org.). Libras e surdez: conceitos e aplicações na educação de Surdos. São Paulo: Garcia Edizioni, 2018, p. 177-199.

FARIAS, Francisca Neuza de Almeida; LUSTOSA, Ana Valéria Marques Fortes. O surdo em busca de uma educação de qualidade. In: FARIAS, Francisca Neuza de Almeida; LIMA, Ediane Silva (org.). Libras e surdez: conceitos e aplicações na educação de Surdos. São Paulo: Garcia Edizioni, 2018, p.125-156.

GOMES, Ciro. Nada mais será como antes. In: TOSTES, Anjuli.; MELO FILHO, Hugo.Quarentena: reflexões sobre a pandemia e depois. Bauru: Canal 6Editora, 2020, p. 51-60.

IBGE. Estatísticas de gênero. 2010. Disponível em:

https://www.ibge.gov.br/apps/snig/v1/?loc $=0 \&$ cat $=-1,-2,-3,128 \&$ ind $=4643$. Acesso em: 3 de out de 2020 .

LACERDA, Cristina B. F. de. O intérprete de Língua de Sinais (ILS). In: LODI, Ana Claudia B.; MELO, Ana Dorziat B.; FERNANDES, Eulalia. (org.). Letramento, bilinguismo e educação de surdos. Porto Alegre: Mediação, 2012, p. 262-277.

MARTINS, Diléia Aparecida. Trajetória de formação e condições de trabalho do 
intérprete de libras em instituições de educação superior. 2009. $121 \mathrm{f}$. Dissertação(Mestrado em Educação) - Pontifícia Universidade Católica de Campinas, Campinas, 2009.

MÉLO, A. D. B. de.; ARAújO, J. R. de.; SOARES, F. P. S. O direito dos surdos à educação (um estudo com jovens de 14 a 22 anos). In: LODI, Ana Claudia Balieiro; MELO, Ana Dorziat B.; FERNANDES, Eulalia (org.). Letramento, bilinguismo e educação de surdos. Porto Alegre: Mediação, 2012, p. 351-368.

NASCIMENTO, Vinícius. Janelas de libras e gêneros do discurso: apontamentos para a formação e atuação de tradutores de língua de sinais. Trabalhos em Linguística Aplicada, Campinas, v. 56, n. 2, p. 461-492, 2017.

ORGANIZAÇÃO MUNDIAL DA SAÚDE. Folha informativa sobre COVID-19. Disponível em: https://www.paho.org/pt/covid19. Acesso em: 5 de out. 2020.

PIAUÍ. Governo do Estado. Coronavírus Piauí. Disponível em: http://coronavirus.pi.gov.br/. Acesso em: 15 de outubro. 2020.

QUADROS, Ronice Müller de. O tradutor e interprete de Língua Brasileira de Sinais e Língua Portuguesa: programa nacional de apoio à educação de surdos. Brasília, DF:SEESP, 2004.

RAFAEL, Ricardo de Mattos Russo et al. Epidemiologia, políticas públicas e Covid-19. Revista Enfermagem UERJ, Rio de Janeiro, v. 28, p. 1-6, 2020. Disponível em: https://www.e-

publicacoes.uerj.br/index.php/enfermagemuerj/article/view/49570/33134. Acesso em: 3 out. 2020.

SANTOS, Boaventura de Sousa. Vírus: tudo o que é sólido desmancha no ar. In: TOSTES, Anjuli; MELO FILHO, Hugo. (org.). Quarentena: reflexões sobre a pandemia e depois. Bauru: Canal 6, 2020. p. 45-49.

SANTOS, Joaquim César Cunha dos; NOGUEIRA, Fernanda dos Santos. A tarefa do tradutor-intérprete de Língua Brasileira de Sinais/Língua Portuguesa como intelectual específico nas práticas do cuidado de si. In: VIEIRA-MACHADO, Lucyenne Matos da Costa; COSTA JÚNIOR, Euluze Rodrigues da (org.). Educação de surdos: políticas, práticas e outras abordagens. Curitiba: Appris, 2018, p. 179-193.

SEVERO, Valdete Souto. Sobre a Covid-19 e as nossas escolhas. In: TOSTES, Anjuli; MELO FILHO, Hugo. (org.). Quarentena: reflexões sobre a pandemia e depois. Bauru: Canal 6, 2020. p. 219-225.

SILVA, Angela Carrancho da. A representação social da surdez: entre o mundo acadêmico e o cotidiano escolar. In: LODI, Ana Cláudia B.; MELO, Ana Dorziat Barbosa de; FERNANDES, Eulália. (org.). Letramento, bilinguismo e educação de surdos. Porto Alegre: Mediação, 2012. p. 89-101. 
SILVA, Daniele Nunes Henrique. Como brincam as crianças surdas. São Paulo: Plexus, 2002.

TESKE, Ottmar. Surdos: um debate sobre letramentos e minorias. In: LODI, Ana Claudia Balieiro; MELO, Ana Dorziat B.; FERNANDES, Eulalia (org.). Letramento, bilinguismo e educação de surdos. Porto Alegre: Mediação, 2012, p. 27-47.

TOSTES, Anjuli. Pandemia, populismo e nova ordem social. In:TOSTES, Anjuli; Melo FILHO, Hugo.(org.). Quarentena: reflexões sobre a pandemia e depois. Bauru: Canal 6, 2020. p. 31-43.

TOSTES, Anjuli; MELO FILHO, Hugo. Quarentena: reflexões sobre a pandemia e depois. Bauru: Canal 6, 2020. 